\title{
BMJ Open Standard reference values of the upper body posture in healthy young female adults in Germany: an observational study
}

Daniela Ohlendorf, ${ }^{1}$ Vanessa Fisch, ${ }^{1}$ Charlotte Doerry, ${ }^{1}$ Sebastian Schamberger, ${ }^{2}$ Gerhard Oremek, ${ }^{1}$ Hanns Ackermann, ${ }^{3}$ Johannes Schulze ${ }^{1}$

To cite: Ohlendorf D, Fisch V, Doerry C, et al. Standard reference values of the upper body posture in healthy young female adults in Germany: an observational study. BMJ Open 2018;8:e022236. doi:10.1136/ bmjopen-2018-022236

- Prepublication history for this paper is available online. To view these files, please visit the journal online (http://dx.doi. org/10.1136/bmjopen-2018022236).

Received 8 February 2018

Revised 12 June 2018 Accepted 3 July 2018
Check for updates

(C) Author(s) (or their employer(s)) 2018. Re-use permitted under CC BY-NC. No commercial re-use. See rights and permissions. Published by BMJ.

${ }^{1}$ Institute of Occupational, Social and Environmental Medicine, Goethe Universität Frankfurt am Main, Frankfurt, Germany

${ }^{2}$ School of Dentistry, Department of Orthodontics, Goethe-

University Frankfurt, Frankfurt, Germany

${ }^{3}$ Institute of Biostatistics and Mathematical Modeling, Goethe University Hospital, Frankfurt, Germany

Correspondence to

Dr Daniela Ohlendorf;

ohlendorf@med.uni-frankfurt.de

\section{ABSTRACT}

Objective Classifications of posture deviations are only possible compared with standard values. However, standard values have been published for healthy male adults but not for female adults.

Design Observational study.

Setting Institute of Occupational Medicine, Social Medicine and Environmental Medicine, Goethe-University Frankfurt/Main.

Participants 106 healthy female volunteers (21-30 years old; $25.1 \pm 2.7$ years) were included. Their body weight ranged from 46 to $106 \mathrm{~kg}(60.3 \pm 7.9 \mathrm{~kg})$, the heights from 1.53 to $1.82 \mathrm{~m}(1.69 \pm 0.06 \mathrm{~m})$ and the body mass index from $16.9 \mathrm{~kg} / \mathrm{m}^{2}$ to $37.6 \mathrm{~kg} / \mathrm{m}^{2}\left(21.1 \pm 2.6 \mathrm{~kg} / \mathrm{m}^{2}\right)$.

Outcome measures A three-dimensional back scan was performed to measure the upper back posture in habitual standing. The tolerance ranges and $\mathrm{Cl}$ were calculated. Group differences were tested by the Wilcoxon MannWhitney U test.

Results In normal posture, the spinal column was marginally twisted to the left, and the vertebrae were marginally rotated to the right. The kyphosis angle is larger than the lumbar angle. Consequently, a more kyphotic posture is observed in the sagittal plane. The habitual posture is slightly scoliotic with a rotational component (scapular depression right, right scapula marginally more dorsally, high state of pelvic right, iliac right further rotated anteriorly).

Conclusions Healthy young women have an almost ideally balanced posture with minimal ventral body inclination and a marginal scoliotic deviation. Compared with young males, women show only marginal differences in the upper body posture. These values allow a comparison to other studies, both for control and patient data, and may serve as guideline in both clinical practice and scientific studies.

\section{INTRODUCTION}

Various subjective and objective methods to quantify and analyse the body posture have been used, especially for the spinal posture. All prior methods tried to evaluate deformity in the diagnosis and treatment of spinal diseases like scoliosis. $^{1-4}$
Strengths and limitations of this study

Strength: large number of healthy young female participants aged $21-30$ years.

- Strength: video raster stereographic quantitative analysis of the upper back posture.

- Limitation: measurement of the upper body posture only in habitual standing position, not while moving.

- Limitation: external influences (occupational environment) were not assessed which might influence the body posture.

Quantitative analytical methods enable the diagnosis of spinal curvature deviations and/or control the therapeutic effects. The methods vary by their technical complexity and clinical applicability. Roentgenograms or CT scans are frequently used for bone structure deformities, while ultrasound, inclinometer, thermal infrared imaging, scoliometer or video raster stereography are established postural measurement methods. ${ }^{5-10}$ X-ray based methods despite their mutagenic potential still are the gold standard in diagnosis and follow-up of body posture deviations. ${ }^{11-14}$

Video raster stereography has recently been evaluated as an alternative method to quantify vertebral column posture and its deformities. $^{7} 8$ 15-18 Guidelines for orthopaedic rehabilitation in Germany also recommend a follow-up check but do not specify the methods. ${ }^{19}$ The three-dimensional (3D) back scan measures the body geometry between the seventh cervical vertebra and the gluteal cleft. It has high intraclass correlation coefficients and good Cronbach's alpha values for intra-day and interday reliability for all spine parameters. ${ }^{17182021}$ Furthermore, intertester reliability is high. ${ }^{17}$

A 3D surface contour image of the back appears suitable to determine vertebral column deformities, but also to quantify 
the effect of, for example, orthopaedic shoe insoles on the body posture. ${ }^{22}{ }^{23}$ In addition, 3D images can quantify muscular imbalances (kyphotic/lordotic deviations, differences in waist contours, rotation in the shoulder or pelvis) and control the therapeutic success of muscle training in primary, secondary and tertiary prevention. ${ }^{2425}$

Due to the changing workplace environment with its increase in digital work, ever more employees work in a sitting position. Both in the workplace and in the household, this leads to a steady decrease of physical stress on the body. This lack of exercise may result in the development of muscular imbalances and increasing numbers of persons with back pain, currently estimated at 20 million people for Germany. ${ }^{20}$ Back pain due to musculoskeletal disorders can lead to disability or early retirement. Even more frequently, rehabilitation is required to restore the capacity to work in their original occupation.

Early signs of postural disorder, that is, musculoskeletal imbalances should be detected when subjective symptoms have developed, and treated appropriately; in order to assess both diagnosis and treatment effects, quantitative classification criteria are necessary for deviations from normal posture. These deviations should be quantified, for example, in the form of (parametric or non-parametric) percentiles, similar to the Z-score or T-score of bone density. ${ }^{26}$ However, no standard or reference values for body posture currently are published for healthy female subjects; reference values of the upper body posture for healthy men have been published only recently. ${ }^{27}$ Also, classifications of the severity of posture deviations are only possible when deviations from standard or reference values are quantified.

This study measures the upper body posture in healthy women aged 21-30 years by a 3D back scan to provide standard values for the posture of young healthy women. These values and their variances define the normal upper body posture and its variability and may be used to categorise the results of other (orthopaedic) studies. Investigating a homogeneous group of subjects eliminate constitutional, habitual and degenerative changes that could increase both tolerance ranges and CIs. ${ }^{28-31}$

\section{METHODS}

\section{Subjects and public involvement}

One hundred and six female volunteers between 21 and 30 years (25.1 \pm 2.7 years) participated in this study. Their body weight ranged from 46 to $106 \mathrm{~kg}(60.3 \pm 7.9 \mathrm{~kg})$, height from 1.53 to $1.82 \mathrm{~m}(1.69 \pm 0.06 \mathrm{~m})$ and body mass index (BMI) ranged from 16.9 to $37.6 \mathrm{~kg} / \mathrm{m}^{2}$ $\left(21.1 \pm 2.6 \mathrm{~kg} / \mathrm{m}^{2}\right)$. Six per cent of the participants were underweight (BMI $<18.5 \mathrm{~kg} / \mathrm{m}^{2}$ ), $87.8 \%$ of the participants had a normal BMI $\left(18.5-24.9 \mathrm{~kg} / \mathrm{m}^{2}\right), 4.7 \%$ were overweight (BMI $25-29.9 \mathrm{~kg} / \mathrm{m}^{2}$ ) and $0.9 \%$ had obesity I (BMI $30-34.9 \mathrm{~kg} / \mathrm{m}^{2}$ ) according to the WHO weight classification. $^{32}$

All subjects were healthy and free of musculoskeletal symptoms, and therefore no patients were involved.
Using a questionnaire, temporomandibular system disorders were excluded ${ }^{33} ; 95.3 \%$ of the subjects reported to be right-handed and $4.7 \%$ were left-handed; $72.6 \%$ of the participants were students, $27.4 \%$ employees in different occupations (dentists, physicians, teachers, office workers).

All volunteers were healthy (no patients involved) and informed about the study design before giving written informed consent.

\section{Measurement system}

A 3D back scan was performed to quantify the upper back posture while standing, using the back scan system 'MiniRot Kombi' (ABW, Frickenhausen/Germany).

In this system, a projector forms a stripe pattern on the persons bare back; this stripe pattern is captured by an LCD camera from a defined angle. One measurement lasts approximately $2 \mathrm{~s}$. In this way, the back surface is represented as a phase picture which is analysed by an integrated software program reconstructing the 3D image. For calibration of the phase pictures, all test persons are marked at six defined, standardised anatomical locations (figure 1) indicating underlying bone structures. These allow the calculation of 3D parameters (figure 1) with information about rotational movements in the shoulder and pelvic area and the shape of the spine (lordotic, kyphotic and/or scoliotic postures). Artefacts may be caused by different marker placements or movements during the scan, that is, the projection of the stripe pattern on the back, and thus have to be avoided. To measure the body posture, three repeat measurements are taken within 2 min.

During a movement sequence, 15 photos were taken. The maximum picture frequency of the MiniRot Kombi system is more than 50 frames/s with a spatial resolution of $1 / 100 \mathrm{~mm}$. The calculation of the 3D coordinates of the back surface is performed by triangulation. The system error is specified as $<1 \mathrm{~mm}$ (manufacturer information), the reproducibility is limited by the calculations of the upper body posture defined by markers directly on the skin $(<0.5 \mathrm{~mm})$.

\section{Body scans}

The subjects stood barefoot in their habitual body and jaw posture about $90 \mathrm{~cm}$ in front of the back scan apparatus. The arms were hanging loosely; the subjects looked straight fixing the opposite wall.

\section{Evaluation parameter}

From the 3D back scan, three components were quantified: spinal area (markers on C7 and L5), shoulder area (markers at the top of the left/right scapula) and pelvis area (markers on the left/right spina iliaca posterior superior (SIPS)). The marker positions are shown in figure 1, the spine parameters are selected and calculated as described in. ${ }^{27}$

\section{Statistical evaluation}

All calculations were carried out using BIAS V.11.0 (Epsilon Verlag, Darmstadt, Germany). Parameter 

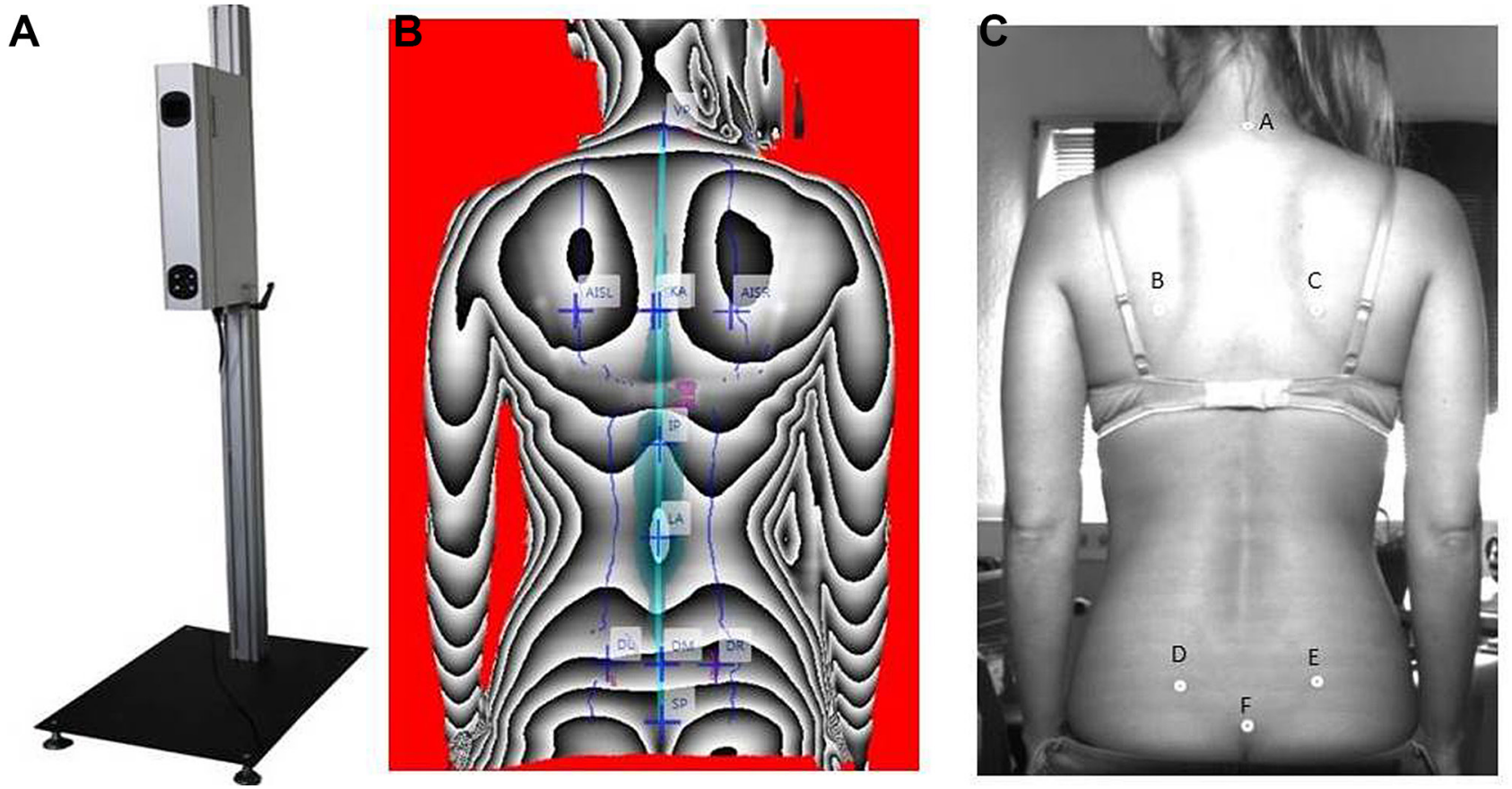

Figure 1 (A) Back scanner MiniRot Combi (ABW, Frickenhausen/Germany), (B) three-dimensional phase picture of the back, (C) marker position on the back-A: vertebra prominens (seventh cervical vertebra); B: lower scapular angle, left; C: lower scapular angle, right; D: spina iliaca posterior superior (SIPS), left; E: SIPS, right; F: sacrum-point (cranial beginning of the gluteal cleft).

distribution was tested by the Kolmogorov-Smirnov test indicating only partially normal distribution; parametric or non-parametric tolerance regions were calculated as defined by the upper and lower limits for $95 \%$ of all values ( \pm 2 SD values), being found in $>95 \%$ of the examined subjects. Values within this range were considered 'normal'.

Furthermore, the two-sided 95\% CI was calculated and indicated the range of the mean or median valuedepending on the distribution quality-and showed the 'accuracy' of these values. For group differences, the t-test or the Wilcoxon Mann-Whitney U test was used.

\section{RESULTS}

Only the constitutional parameter 'body height' was normally distributed, whereas 'body weight' and 'BMI' were not. The median body weight was $60 \mathrm{~kg}$ (tolerance range $49.0-77.28 \mathrm{~kg}$; CI 57 to $62 \mathrm{~kg}$ ). For the BMI, a median of $20.7 \mathrm{~kg} / \mathrm{m}^{2}$ was calculated, with a corresponding tolerance range from 17.99 to $27.2 \mathrm{~kg} / \mathrm{m}^{2}$ and a CI from 20.3 to $21.3 \mathrm{~kg} / \mathrm{m}^{2}$. For the body height, a mean value of $1.69 \mathrm{~m}$ was calculated with a tolerance range between 1.57 and $1.82 \mathrm{~m}$ and a CI of 1.68 to $1.70 \mathrm{~m}$.

Handedness as a relevant parameter had been refused in advance by the t-test and the Wilcoxon Mann-Whitney $\mathrm{U}$ test. All parameters were not significantly different $(\mathrm{p} \geq 0.05)$.

From the back scan values, the posture of an average healthy female person was calculated (tab. 1). On average, the subjects were standing slightly inclined in the anterior line of $3.31^{\circ}$ (tolerance range $8.12^{\circ}$ ventrally to $1.50^{\circ}$ dorsally; confidence range $3.78^{\circ}$ to the left, to $2.85^{\circ}$ to the right).

Laterally, a minimal deviation of the frontal trunk of $0.43^{\circ}$ to the left was seen, the CI $\left(0.18^{\circ}\right.$ right to $0.67^{\circ}$ left) included the perpendicular position; the tolerance interval ranged from $2.91^{\circ}$ to the left, to $2.06^{\circ}$ to the right. In compensation, the axial deviation (inclination between upper body and pelvis) was slightly tilted to the right $\left(0.21^{\circ}\right)$ with a tolerance range of $\pm 4.5^{\circ}$ and a CI of $<1^{\circ}\left(0.25^{\circ}\right.$ left and $0.66^{\circ}$ right $)$. This implied that there were no obvious differences in the inclination between the upper and lower body.

The angle of the thoracic bend was calculated from the distance between the vertebra prominens (VP) and the kyphosis apex and indicated the deviation from the perpendicular line. The median angle was $13.9^{\circ}$, confirming the expected thoracic kyphosis. Here, wider variations were seen with a tolerance range from $6.49^{\circ}$ to $21.31^{\circ}$, and a CI varying from $13.19^{\circ}$ to $14.62^{\circ}$. The lumbar bending angle described the deviation of the distance between the lordosis and kyphosis apex. As compared with the thoracic bend, similar variations of the tolerance value and the CIs were seen in the lumbar region, with a bending angle of $13.17^{\circ}$ (tolerance value $7.83^{\circ}$ to $23.06^{\circ}$; CI $11.90^{\circ}$ to $14.25^{\circ}$ ).

Measurement of the lateral deviation showed a rightsided inclination of the median line by $3.92^{\circ}$ when connecting the points $\mathrm{VP}$ and the centre of the pelvic markers. Both the tolerance range $\left(0.50^{\circ}\right.$ and $7.33^{\circ}$ ,respectively) and the CI $\left(3.59^{\circ} / 4.25^{\circ}\right)$ indicated a rightsided deviation. 
The rotation of the spinal column is a marker of the spinal column torsion and can be measured from the spinal processes. In our analysis, a negative value indicated a rotation to the left and a positive value, to the right. The median rotation was $4.66^{\circ}$, with a tolerance range between $2.04^{\circ}$ and $12.92^{\circ}$, and a CI between $4.18^{\circ}$ and $5.29^{\circ}$. Consequently, on average a right-sided spinal rotation was found.

The kyphosis and lordosis angle have a mean or a median of $51.66^{\circ}$ and $46.29^{\circ}$, with a substantial tolerance range of approximately $\pm 25^{\circ}$ and a CI of about $\pm 2^{\circ}$.

Shoulder parameters are valid indicators for upper body posture (tab. 1), too. The lower scapular spinae were measured by fixed markers; the interscapular distance as indicator of the variability of the upper body was $150.56 \mathrm{~mm}$, with a tolerance range of $110.51-$ $190.60 \mathrm{~mm}$, and a confidence limit of $146.68-154.43 \mathrm{~mm}$. The scapular height (deviation from the horizontal line) refers to a slightly lower left shoulder blade (by $1.28^{\circ}$ ), whereas the upper and lower limit of the range markers were $-22.36^{\circ}$ and $19.81^{\circ}$, so that the left shoulder blade is more caudally in the lower limit and more cranially in the upper limit. The same variation is shown by the data of the CI, with values of $-3.32^{\circ}$ (left scapula higher) and $-0.76^{\circ}$ (right scapula higher).

The shoulder markers illustrated the right shoulder being slightly further dorsal by $3.06^{\circ}$, with a tolerance range of $-3.26^{\circ}$ to $9.37^{\circ}$ and a CI of $2.44^{\circ}$ to $3.67^{\circ}$. Only minor differences were seen between the left and right shoulder blade angles, with the right shoulder $2.6^{\circ}$ (median) more caudally.

Table 1 also compiles the pelvic parameters. The distance for the SIPS markers refers to the pelvic width, which on average is $99.56 \mathrm{~mm}$ (tolerance range 74.76$122.37 \mathrm{~mm}$, CI 97.17 and $101.96 \mathrm{~mm}$ ).

The deviation of the pelvic height (in degrees) from the horizontal plane is very low. Both differences in pelvic height (in $\mathrm{mm}$ ) and deviations from the horizontal line

Table 1 Spine, shoulder and pelvis parameter: mean value, median, tolerance regions (upper and lower limit), $\mathrm{Cl}$ (left and right limit)

\begin{tabular}{|c|c|c|c|c|c|}
\hline & $\begin{array}{l}\text { Mean value/ } \\
\text { median }\end{array}$ & $\begin{array}{l}\text { Tolerance range, } \\
\text { lower limit }\end{array}$ & $\begin{array}{l}\text { Tolerance range, } \\
\text { upper limit }\end{array}$ & $\mathrm{Cl}$, left limit & CI, right limit \\
\hline \multicolumn{6}{|l|}{ Spine parameter } \\
\hline Trunk length $\mathrm{D}(\mathrm{mm})$ & 461.31 & 412.95 & 509.67 & 456.64 & 465.99 \\
\hline Trunk length S (mm) & 509.52 & 458.88 & 560.15 & 504.62 & 514.41 \\
\hline Sagittal trunk decline $\left(^{\circ}\right)$ & -3.31 & -8.12 & 1.5 & -3.78 & -2.85 \\
\hline Frontal trunk decline $\left({ }^{\circ}\right)$ & -0.43 & -2.91 & 2.06 & -0.67 & -0.18 \\
\hline Axis decline $\left({ }^{\circ}\right)$ & 0.21 & -4.45 & 4.86 & -0.25 & 0.66 \\
\hline Thoracic bending angle $\left(^{\circ}\right)$ & 13.9 & 6.49 & 21.31 & 13.19 & 14.62 \\
\hline Lumbar bending angle $\left({ }^{\circ}\right)$ & 13.17 & 7.83 & 23.06 & 11.9 & 14.25 \\
\hline SD lateral deviation $(\mathrm{mm})$ & 3.92 & 0.5 & 7.33 & 3.59 & 4.25 \\
\hline Maximal lateral deviation $(\mathrm{mm})$ & -5.35 & -12.8 & 12.38 & -5.76 & -0.89 \\
\hline$S D$ rotation $\left({ }^{\circ}\right)$ & 4.66 & 2.04 & 12.92 & 4.18 & 5.29 \\
\hline Maximal rotation $\left(^{\circ}\right)$ & 9.2 & -9 & 37.48 & 8 & 10.76 \\
\hline Kyphosis angle $\left({ }^{\circ}\right)$ & 51.66 & 27.91 & 74.42 & 49.37 & 53.96 \\
\hline Lordosis angle $\left({ }^{\circ}\right)$ & 46.29 & 21.66 & 70.92 & 43.91 & 48.67 \\
\hline \multicolumn{6}{|l|}{ Shoulder parameter } \\
\hline Scapular distance $(\mathrm{mm})$ & 150.56 & 110.51 & 190.6 & 146.68 & 154.43 \\
\hline Scapular height $\left({ }^{\circ}\right)$ & -1.28 & -22.36 & 19.81 & -3.32 & 0.76 \\
\hline Scapular rotation $\left(^{\circ}\right)$ & 3.06 & -3.26 & 9.37 & 2.44 & 3.67 \\
\hline Scapular angle left $\left({ }^{\circ}\right)$ & 28.54 & 16.49 & 62.74 & 27.36 & 30.74 \\
\hline Scapula angle right $\left({ }^{\circ}\right)$ & 31.17 & 10.61 & 73 & 27.2 & 34.62 \\
\hline \multicolumn{6}{|l|}{ Pelvis parameter } \\
\hline Pelvis distance $(\mathrm{mm})$ & 99.56 & 74.76 & 124.37 & 97.17 & 101.96 \\
\hline Pelvis height $\left({ }^{\circ}\right)$ & 0.76 & -4.29 & 5.81 & 0.28 & 1.25 \\
\hline Pelvis height (mm) & 1.34 & -7.33 & 10.01 & 0.5 & 2.18 \\
\hline Pelvis torsion $\left(^{\circ}\right)$ & 0.24 & -6.89 & 7.36 & -0.45 & 0.93 \\
\hline Pelvis rotation $\left({ }^{\circ}\right)$ & 2.2 & -5.72 & 7.34 & 1.49 & 2.76 \\
\hline
\end{tabular}

Italic data are non-parametric values. 
(in degrees) indicate a slightly higher position of the right pelvis by approximately $1^{\circ}$ or $1 \mathrm{~mm}$ (tab. 4). The same applies to the pelvic torsion and rotation, so that the right iliac marker is rotated posteriorly and simultaneously tilted further ventral (mean pelvis torsion: $0.24^{\circ}$; mean pelvic rotation: $2.2^{\circ}$ ).

\section{DISCUSSION}

This paper presents normal values and normal ranges including tolerance and CIs for the body posture of healthy young females. Height, weight and BMI of the participants are comparable with average young German female persons, ${ }^{34}{ }^{35}$ as measured by Mensink $e t$ $a l^{34}$ in over 7000 adults from the general German population. The age-matched female group from Mensink et $a l^{34}$ was $3.20 \mathrm{~cm}$ smaller, $4.92 \mathrm{~kg}$ heavier and thus also had a slightly higher BMI by $2.58 \mathrm{~kg} / \mathrm{m}^{2}$ compared with our values. Similar findings have been reported by the German Federal Statistical Office in 2011 for 2009, ${ }^{35}$ which correlate even better with our results. ${ }^{34}$ Data for height, weight and BMI, obtained to assess the prevalence of obesity in Germany between 1985 and 2002, ${ }^{36}$ in 1504 female volunteers (25-29 years) show that the subjects in our study are marginally taller, lighter and have a lower BMI.

In this context, however, it should be borne in mind that this study mainly involved students and university employees with the same lifestyle, with values slightly differing from the general population, and a likely over-representation of participants with a high social status.

Of the total participants in this study, $87.8 \%$ had a normal BMI, 22.3\% more than Mensink $e t a l^{34}$ found for women aged 18-29years. The relation of overweight with social status is well known; this confounder is also seen by the data from Mensink $e t a l^{34} ; 36.9 \%$ of women with a low social status were overweight, $16.4 \%$ obese compared with $18.7 \%$ overweight and $4.4 \%$ obese women with a high social status. Helmert et $a l^{36}$ calculated similar data using the equivalent household income; thus the different BMI values likely are explained by the participant selection preferentially from the students of the School of Dentistry in our university, with a high social status.

The back scan values indicate a characteristic posture of young females. Only small deviations from an ideal perpendicular position are noted; the ventral tilt of the trunk, the lateral deviation and rotation of the spine, shoulder and pelvis were very small. The posture is marginally scoliotic (the ventral trunk tilts marginally to the left side, the scapula is higher on the left side, the pelvis slightly elevated on the right side) with an expected rotatory component (a lumbar right tilt to compensate for the left-tilted ventral trunk, a slight twist of the processus spinosus to the right, the right scapula marginally more dorsal, the SIPS of the right iliac bone rotated anteriorly) (tab. 1). The spinal curve, defined by the thoracic and lumbar bending angle and the kyphosis and lordosis angle, indicates that the angle in the thoracic spine area is marginally larger than that in the lumbar region (tab. 1 ), and a slightly kyphotic posture in the sagittal plane can be observed.

Handedness has no influence on these parameters which should be expected from the observed symmetry. However, since $95.3 \%$ of the participants were righthanded, no firm conclusions can be drawn for left-handed people. Also, whether an influence of the dominant leg ${ }^{37}$ exists on the posture cannot be answered by our results. Appropriate test methods for the determination of these components should be used in further studies.

A gender comparison ${ }^{27}$ shows only marginal differences in the upper body posture. Both studies used the same measurement system and data evaluation and thus allow a direct comparison of the values. Although the female upper body appears narrower and more delicate due to the weaker muscular shoulder girdle and the smaller chest, the ratio between chest and shoulder width is the same. ${ }^{38}$

The anatomical and constitutional differences are confirmed by the present data. In terms of the shoulder width, the fixed scapular landmarks indicate a larger distance of $2.9 \mathrm{~cm}$ in men than in women (table 1). In contrast, men have a smaller pelvis calculated from the SIPS markers (6 $\mathrm{mm}$ difference) which results in a wider shoulder than pelvis distance by $8.5 \mathrm{~cm}$ in men, but only $5.0 \mathrm{~cm}$ in women, confirming and quantifying the wellknown gender-specific anatomical differences.

In addition to these constitutional differences, differences in the lordotic and kyphotic angles are calculated from the spinal column parameters. Thus, women have an average kyphotic angle of $52^{\circ}$, men of $46^{\circ}$; the lordosis angle is $46^{\circ}$ for women and $31^{\circ}$ for men. Thus, the spinal curvature in the thoracic and lumbar spine area is more pronounced in women than in men. The difference in the lordosis angle between the sexes is about $15^{\circ}$ and in the case of the kyphotic angle with approximately $6^{\circ}$, however, men have an approximately $15^{\circ}$ greater thoracic kyphosis angle than lumbar lordosis angle in contrast to a $6^{\circ}$ difference of women. Consequently, the kyphosis angle is larger than the lordosis angle in both sexes, women are in a more balanced posture due to the smaller difference between the two angles.

Liu $e$ t $a l^{39}$ tried to define standard parameters of cervical spine alignment and range of motion related to age, sex and cervical disc. These results underline the more pronounced thoracic kyphosis in women. The greater lumbar lordosis of the females can be traced back to sex differences in the pelvic shape: the wider pelvic blades of the female pelvis have a larger angle between the pubic branches, a larger transverse pelvic diameter and are lower. Thus, the pronounced female pelvic tilt leads to a larger lumbar lordosis. Consequently, a larger lumbar lordosis causes a thoracic hyperkyphosis. These (different) compensations are seen in the pelvic position in both sexes. ${ }^{38}$ This position of the lumbar spine also affects the extent of the movement in the 
flexion-extension testing of the trunk. The total task-specific hip motion ranges as measured from erect standing to the maximum flexion were higher in females than in males. $^{40}$

Furthermore, the same authors report that female patients with chronic low back pain had higher regional hip and trunk motion ranges than male patients. ${ }^{41}$ Why women have a larger lordosis angle currently is unknown. An extensive literature search in PubMED and other databases did not retrieve any published hypothesis. An explanation of physiological differences, however, has been forwarded to comparable sex differences in the pelvic anatomy for rodents and has been related to sexual behaviour in these animals. Guinea pigs show hormonally controlled, gender-related reproductive behaviour: male guinea pigs show a distinct sexual approach consisting of body raising, intromission and ejaculation, and female guinea pigs respond with a corresponding conceiving position of a predominantly lordotic lumbar posture. 424 At least for this species, the observed anatomical differences may translate directly into an apt reproductive behaviour. In both species, the pelvis itself has the same position in both sexes in a relaxed posture, and is positioned almost horizontally.

No similar explanation exists for differences in the shoulder region parameters either; the right shoulder is positioned more caudal in both sexes, but women have 'deeper' shoulders (increased scapular angle right/left).

All other positional parameters are nearly identical between men and women, with the differences being smaller than the margin of error, and likely have no clinical relevance.

The 3D back scan is a fast, non-contact method to quantify the body posture and is suitable for measuring body postures in both healthy persons and patients. It can quantify pathological positions like scoliosis, kyphosis, leg-length differences and functional movement disorders, as well as improvements by medical treatment. The chances and limitations of the measurement system and procedure ${ }^{44-50}$ have already been discussed by Ohlendorf et $a l^{27}{ }^{51}$ In the future, this method may allow to grade postural deviations, for example, by a grading system using the tolerance ranges for men and women, as has been done for bone densitometry in the t-scale and z-scale. ${ }^{26}$

\section{CONCLUSION}

Video raster stereography is a method to quantitatively measure the human 3D back surface. Healthy young women have an almost ideally balanced posture with minimal ventral body inclination and a marginal scoliotic deviation. In comparison with men, women have only small differences in upper body posture, with nearly identical normal values. These values allow a quantitative comparison with other studies for control and patient data, and may serve as an orientation in both clinical practice and scientific studies. Further studies could expand this method to age-related changes in body posture, quantitative assessments of postural changes in relevant diseases and improvements by therapeutic interventions.

Acknowledgements This article contains parts of the doctoral thesis of V Fisch.

Contributors DO, VF, CD, SS, G0 and JS made substantial contributions to the conception and design of the manuscript. D0, VF and CD made substantial contributions to the construction of the measurement protocol and HA and DO have been involved in the statistical data analysis. All authors have read and approved the final manuscript.

Funding The authors have not declared a specific grant for this research from any funding agency in the public, commercial or not-for-profit sectors.

Competing interests None declared.

Patient consent Not required.

Ethics approval The local medical ethics committee of the medical faculty (Goethe-University Frankfurt; No. 303/16).

Provenance and peer review Not commissioned; externally peer reviewed.

Data sharing statement № additional data available.

Open access This is an open access article distributed in accordance with the Creative Commons Attribution Non Commercial (CC BY-NC 4.0) license, which permits others to distribute, remix, adapt, build upon this work non-commercially, and license their derivative works on different terms, provided the original work is properly cited, appropriate credit is given, any changes made indicated, and the use is non-commercial. See: http:// creativecommons.org/licenses/by-nc/4.0/.

\section{REFERENCES}

1. Corona J, Sanders JO, Luhmann SJ, et al. Reliability of radiographic measures for infantile idiopathic scoliosis. J Bone Joint Surg Am 2012;94:e86-1-8.

2. Langensiepen $\mathrm{S}$, Semler $\mathrm{O}$, Sobottke R, et al. Measuring procedures to determine the Cobb angle in idiopathic scoliosis: a systematic review. Eur Spine J 2013;22:2360-71.

3. Prowse A, Pope R, Gerdhem P, et al. Reliability and validity of inexpensive and easily administered anthropometric clinical evaluation methods of postural asymmetry measurement in adolescent idiopathic scoliosis: a systematic review. Eur Spine $J$ 2016;25:450-66.

4. Prowse A, Aslaksen B, Kierkegaard M, et al. Reliability and concurrent validity of postural asymmetry measurement in adolescent idiopathic scoliosis. World J Orthop 2017;8:68-76.

5. Kuklo TR, Potter BK, Schroeder TM, et al. Comparison of manual and digital measurements in adolescent idiopathic scoliosis. Spine 2006;31:1240-6.

6. Zheng YP, Lee TT, Lai KK, et al. A reliability and validity study for Scolioscan: a radiation-free scoliosis assessment system using 3D ultrasound imaging. Scoliosis Spinal Disord 2016;11:13.

7. Betsch M, Rapp W, Przibylla A, et al. Determination of the amount of leg length inequality that alters spinal posture in healthy subjects using rasterstereography. Eur Spine J 2013;22:1354-61.

8. Drerup B. Rasterstereographic measurement of scoliotic deformity. Scoliosis 2014;9:22.

9. Abate M, Carlo LD, Romualdo SD, et al. Postural adjustment in experimental leg length difference evaluated by means of therma infrared imaging. Physiol Meas 2010;31:35-43.

10. Coelho DM, Bonagamba GH, Oliveira AS. Scoliometer measurements of patients with idiopathic scoliosis. Braz J Phys Ther 2013;17:179-84.

11. Ronckers CM, Land CE, Miller JS, et al. Cancer mortality among women frequently exposed to radiographic examinations for spinal disorders. Radiat Res 2010;174:83-90.

12. Levy AR, Goldberg MS, Hanley JA, et al. Projecting the lifetime risk of cancer from exposure to diagnostic ionizing radiation for adolescent idiopathic scoliosis. Health Phys 1994;66:621-33.

13. Nash CL, Gregg EC, Brown RH, et al. Risks of exposure to X-rays in patients undergoing long-term treatment for scoliosis. J Bone Joint Surg Am 1979;61:371-4.

14. Goldberg MS, Mayo NE, Levy AR, et al. Adverse reproductive outcomes among women exposed to low levels of ionizing radiation from diagnostic radiography for adolescent idiopathic scoliosis. Epidemiology 1998;9:271-8. 
15. Betsch M, Wild M, Große B, et al. The effect of simulating leg length inequality on spinal posture and pelvic position: a dynamic rasterstereographic analysis. Eur Spine J 2012;21:691-7.

16. Wild M, Kühlmann B, Stauffenberg $A$, et al. Does age affect the response of pelvis and spine to simulated leg length discrepancies? A rasterstereographic pilot study. Eur Spine J 2014;23:1449-56.

17. Melvin M, Mohokum M, Sylvia M, et al. Reproducibility of rasterstereography for kyphotic and lordotic angles, trunk length, and trunk inclination: a reliability study. Spine 2010;35:1353-8.

18. Mohokum M, Schülein S, Skwara A. The Validity of Rasterstereography: A Systematic Review. Orthop Rev 2015;7:5899.

19. Kladny B, Santos Leal E, Schneider L, et al. Spezielles Rehabilitationskonzept Wirbelsäulendeformitäten. Eine Leitlinie der Sektion Rehabilitation und Physikalische Medizin der DGOOC von Orthopäden für Orthopäden AWMF online 2012.

20. Guidetti L, Bonavolontà V, Tito A, et al. Intra- and interday reliability of spine rasterstereography. Biomed Res Int 2013;2013:1-5.

21. Schroeder J, Reer R, Braumann KM. Video raster stereography back shape reconstruction: a reliability study for sagittal, frontal, and transversal plane parameters. Eur Spine J 2015;24:262-9.

22. Park SM, Ahn SH, Lee AY, et al. Raster-stereographic evaluation of the effects of biomechanical foot orthoses in patients with scoliosis. J Phys Ther Sci 2016;28:1968-71.

23. Ohlendorf D. Mit Einlegesohlen die Körperstatik verbessern. Extracta Orthopaedica. , 2010:1, 8-10.

24. Ohlendorf D. Methoden und Mittel zur Verbesserung des statischen und dynamischen Muskelverhaltens bei haltungsbedingten Beschwerden - ein trainings- und bewegungswissenschaftlicher Vergleich zwischen sensomotorischen, haltungsverbessernden Einlegesohlen und gesundheitsorientiertem, rehabilitativem Muskelaufbautraining. Göttingen: Dissertations at Georg-August-Universität Göttingen, 2008.

25. Anwer S, Alghadir A, Abu Shaphe M, et al. Effects of Exercise on Spinal Deformities and Quality of Life in Patients with Adolescent Idiopathic Scoliosis. Biomed Res Int 2015;2015:1-15.

26. Bazzocchi A, Ponti F, Diano D, et al. Trabecular bone score in healthy ageing. Br J Radiol 2015;88:20140865.

27. Ohlendorf D, Adjami F, Scharnweber B, et al. Standard values of the upper body posture in male adults. Advances in Clinical and Experimental Medicine 2017. accepted for publication.

28. Abubaker AO, Raslan WF, Sotereanos GC. Estrogen and progesterone receptors in temporomandibular joint discs of symptomatic and asymptomatic persons: a preliminary study. J Oral Maxillofac Surg 1993;51:1096-100.

29. Bush FM, Harkins SW, Harrington WG, et al. Analysis of gender effects on pain perception and symptom presentation in temporomandibular pain. Pain 1993;53:73-80.

30. Conti PC, Ferreira PM, Pegoraro LF, et al. A cross-sectional study of prevalence and etiology of signs and symptoms of temporomandibular disorders in high school and university students. J Orofac Pain 1996;10:254-62.

31. Nordström G, Eriksson S. Longitudinal changes in craniomandibular dysfunction in an elderly population in northern Sweden. Acta Odontol Scand 1994;52:271-9.

32. WHO. Obesity: preventing and managing the global epidemic. Report of a WHO consultation 2000;894:1-253.
33. Kopp S. Okklusale und klinisch funktionelle Befunde im craniomandibulären System bei Kindern und Jugendlichen. Jena: Medizinische Habilitation 2005.

34. Mensink GBM, Schienkiewitz A, Haftenberger M, et al. Übergewicht und Adipositas in Deutschland. Bundesgesundheitsblatt Gesundheitsforschung Gesundheitsschutz 2013;56:786-94.

35. Bundesamt S. Mikrozensus - Fragen zur Gesundheit - Körpermaße der Bevölkerung Wiesbaden. 2011 https://www.destatis.de/DE/ Publikationen/Thematisch/Gesundheit/Gesundheitszustand/Koer permasse5239003099004.pdf?_blob=publicationFile (cited 12 Nov 2015).

36. Helmert U, Strube H. Die Entwicklung der Adipositas in Deutschland im Zeitraum von 1985 bis 2002. Gesundheitswesen 2004:66:409-15.

37. Fischer K. Rechts-Links-Probleme in Sport und Training. Studien zur angewandten Lateralitätsforschung. Schorndorf: Hofmann Verlag, 1988.

38. Weineck J. Sportbiologie: Spitta, 2004.

39. Liu B, Wu B, Van Hoof T, et al. Are the standard parameters of cervical spine alignment and range of motion related to age, sex, and cervical disc degeneration? J Neurosurg Spine 2015;23:274-9.

40. Kienbacher T, Paul B, Habenicht R, et al. Age and gender related neuromuscular changes in trunk flexion-extension. $J$ Neuroeng Rehabil 2015;12:3.

41. Kienbacher T, Fehrmann E, Habenicht R, et al. Age and gender related neuromuscular pattern during trunk flexion-extension in chronic low back pain patients. J Neuroeng Rehabil 2016;13:16.

42. Kudwa AE, Bodo C, Gustafsson JA, et al. A previously uncharacterized role for estrogen receptor beta: defeminization of male brain and behavior. Proc Natl Acad Sci U S A 2005;102:4608-12.

43. Phoenix CH, Goy RW, Gerall AA, et al. Organizing action of prenatally administered testosterone propionate on the tissues mediating mating behavior in the female guinea pig. Endocrinology 1959;65:369-82.

44. Asamoah V, Mellerowicz $\mathrm{H}$, Venus $\mathrm{J}$, et al. [Measuring the surface of the back. Value in diagnosis of spinal diseases]. Orthopade 2000;29:480-9.

45. Diers H. Optische Wirbelsäulen- und Haltungsvermessung. Orthopädietechnik 2008;38:479-84.

46. Drerup B. Improvements in measuring vertebral rotation from the projections of the pedicles. J Biomech 1985;18:369-78.

47. Drerup B, Hierholzer E. Objective determination of anatomical landmarks on the body surface: measurement of the vertebra prominens from surface curvature. J Biomech 1985;18:467-74.

48. Drerup B, Hierholzer E. Automatic localization of anatomical landmarks on the back surface and construction of a body-fixed coordinate system. J Biomech 1987;20:961-70.

49. Hierholzer E. Objektive Analyse der Rückenform von Skoliosepatienten. Stuttgart: Gustav Fischer Verlag, 1993.

50. Hübner J. Handbook Formetric III. Schlangenbad: Diers International $\mathrm{GmbH}, 2007$.

51. Ohlendorf D, Mickel C, Filmann N, et al. Standard values of the upper body posture and postural control: a study protocol. J Occup Med Toxicol 2016;11. 